\title{
Jean-Pierre Deffontaines, un regard, une main
}

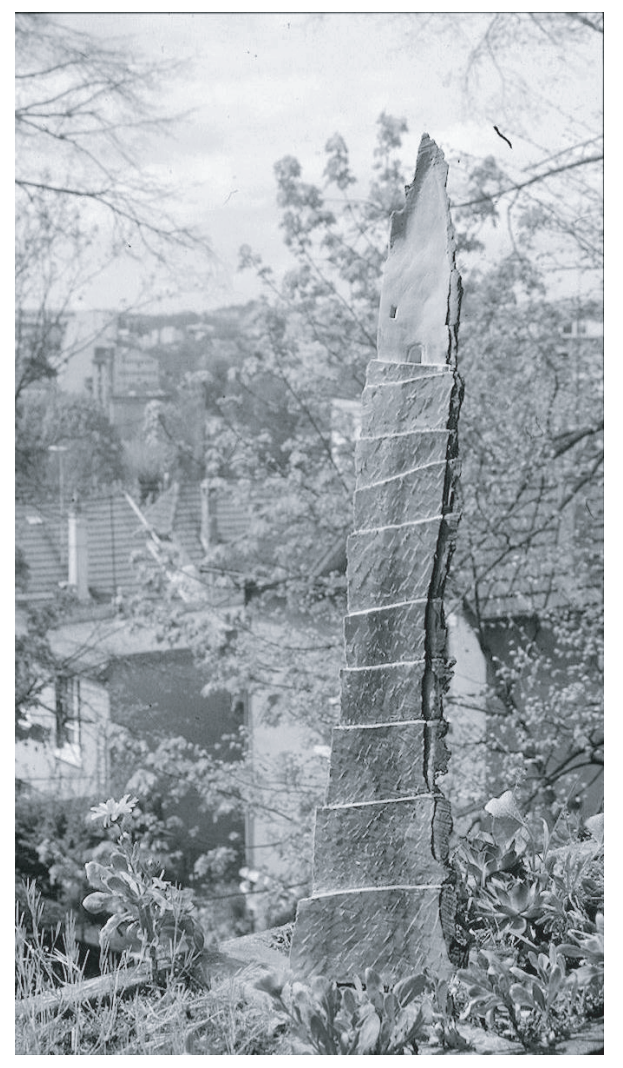

«[...] Il me semble que la création débute par la rencontre d'une idée et d'une forme. Depuis 25 ans je travaille le bois. Des bois repérés en marchant dans les forêts, les parcs et jardins. Est-ce la forme du bois qui déclanche l'idée? Est-ce une idée plus ou moins consciente qui se reconnaît dans une ébauche de forme? [...]

Sur l'une de ces formes, de façon inattendue, s'accroche une idée. Mais quand on veut imposer l'idée, l'échange avec le bois est souvent décevant. Il faut le laisser parler. Comme dans le cas du berger qui garde en alpage et qui prend en compte le «biais " du troupeau, son comportement territorial naturel, son désir. Il faut composer avec le biais du bois. [... $]^{1} »$

Photo. 1. Pavillon de banlieue (1995), peuplier tremble de Saint-Léger-en-Yvelines. (C) J.-P. Deffontaines.)

«[...] La sculpture me semble une découverte d'une facette inattendue de soi, d'une aptitude à créer un objet qui relie la forme et l'idée et dans lequel on se reconnaît. L'objet est là, que l'on transforme. Il existe, on peut le contourner, il vous regarde, on peut le caresser. La sculpture m'apparaît un équilibre. [...]»

Photo. 2. New York (1993), chêne de Pierrefontaine (Doubs). ( J.-P. Deffontaines.)

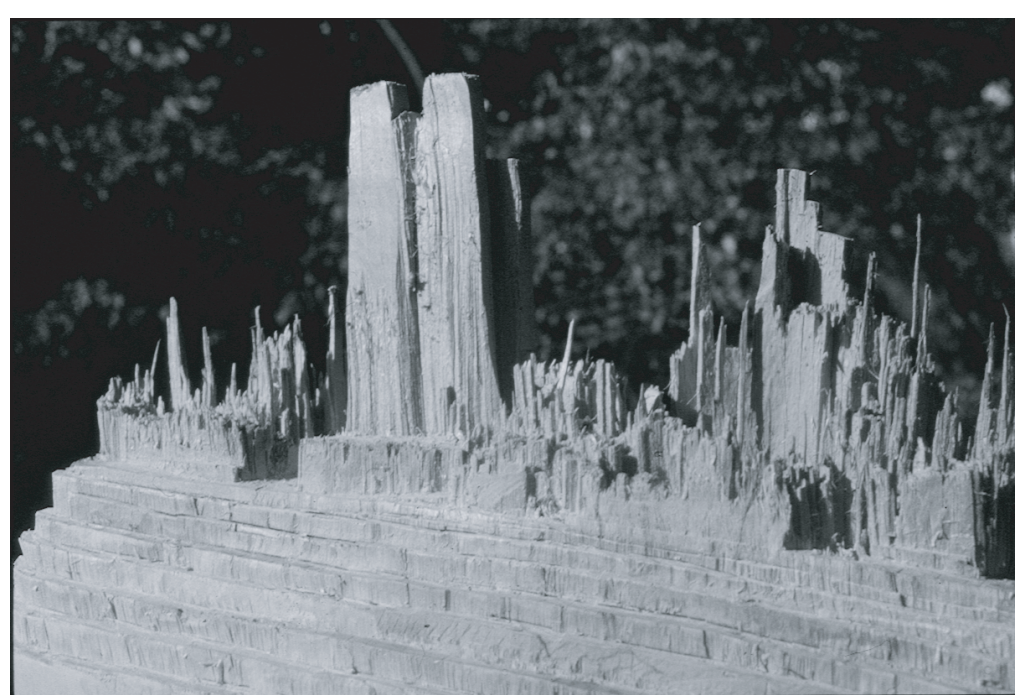

${ }^{1}$ Ces extraits sont tirés d'un texte écrit par J.-P. Deffontaines le 25 février 2005. 


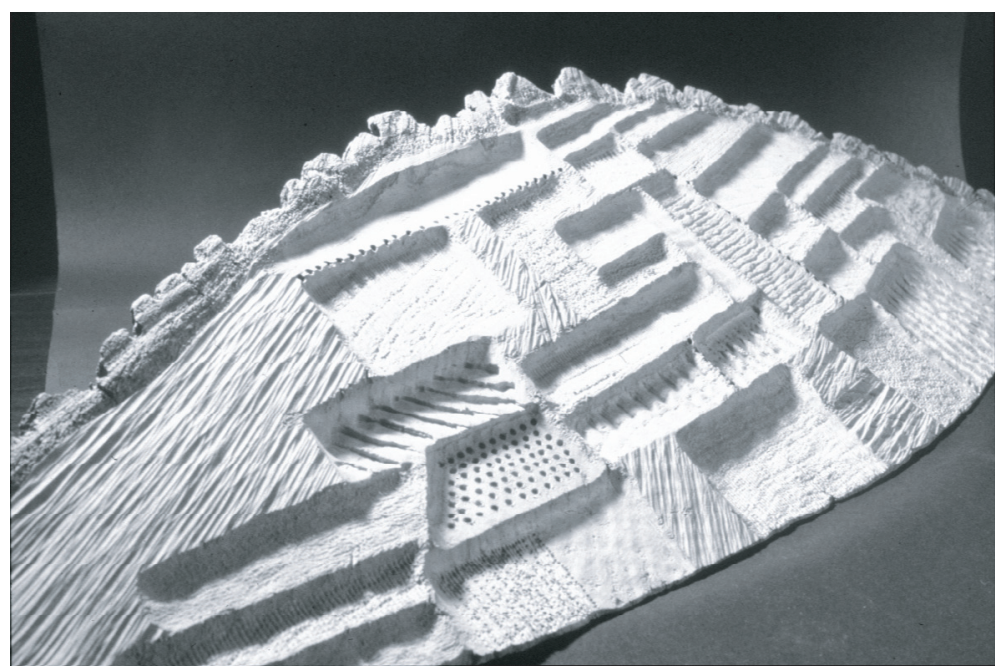

Photo. 3. La côte champenoise (1996). Tilleul du parc du château de Versailles (Yvelines). (c) J.-P. Deffontaines.)

"[...] l'objet est soumis aux regards, donc au jugement des autres. [...] Le regard des autres est devenu un complément obligatoire, à la fois source de signification, de renouvellement et de satisfaction. [...] Je me suis rendu compte que l'objet permettait d'établir des liens, fondements du sens de la vie.»

Photo. 4. Plans paysages : Méditerranée, bocage, terrasses, montagne, alpage (1985). Terre.

(c) J.-P. Deffontaines.)

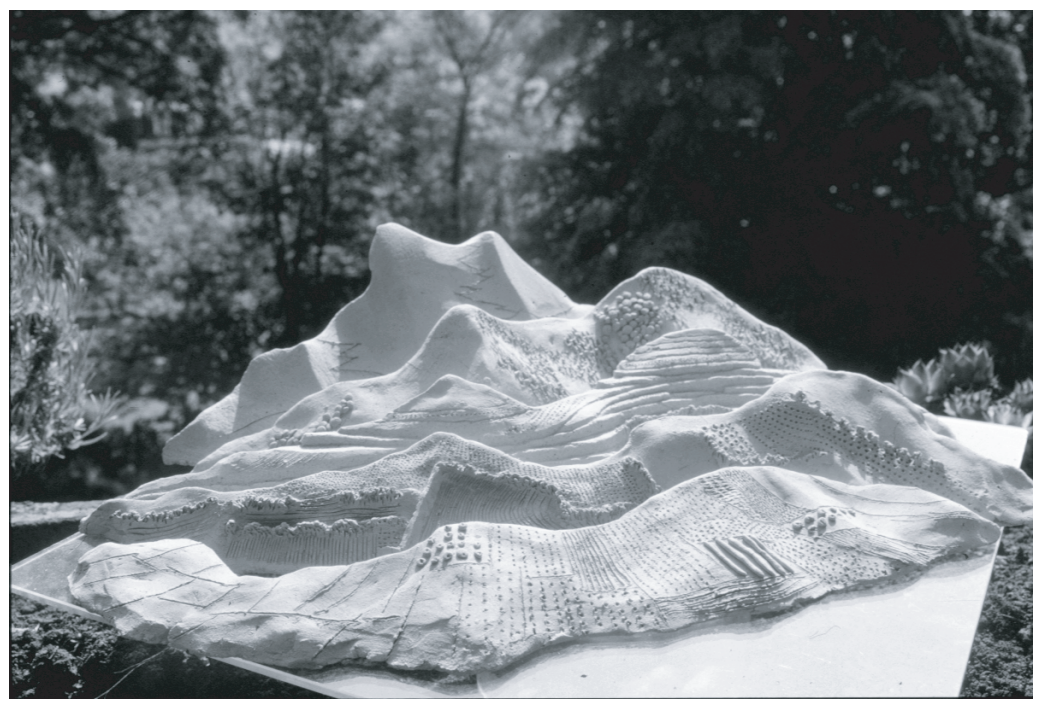

To access this journal online: www.edpsciences.org 